\title{
From Manual to Multimedia: Development of an Enterprise Game
}

Susanna Virtanen, Riitta Smeds, Matti Gröhn, Janne Ikäheimonen, Janne Jalkanen, Hanna Kervinen, Seppo Laukkanen TAI Research Centre, Helsinki University of Technology

E-mail: susanna.virtanen@hut.fi, riitta.smeds@hut.fi,matti.grohn@hut.fi, ikis@cc.hut.fi, jalkanen@cs.hut.fi, kervinen@iki.fi,seppo@simlab.hut.fi

Key words: enterprise simulation, multimedia, training, games, virtual reality

Abstract: The paper describes an on-going process of developing a generic, modular Enterprise Game. The game integrates conceptual, computational, visual and social enterprise models into a comprehensive 'virtual enterprise', in which the participants can jointly operate and experience business processes. Enterprise Game One focuses on the order-to-delivery process. Its increasing level of computerization and visualization towards a multimedia supported game is described, comparing the different game prototypes.

\section{INTRODUCTION}

Games and simulations have proven efficient training methods to fulfill the requirements of the modern, fast-moving business environment. These methods consider the participants as active experimenters and learners: through concrete action and decision making in the game, they experience in a compact way, how the enterprise functions. Multimedia can be used during the game and simulation sessions to support this learning process. Computer aided learning process and multimedia both make a learning session more visual, interactive and efficient which strengthens the learning influence (Riis et al. 1998, Schank 1997). 
In the three-year research and development project SimLab 1998-2000 at Helsinki University of Technology, an Enterprise Game is being developed to the training needs of industry and education (cf. Smeds et al. 1999, http://www.simlab.hut.fi). The development work is done in cooperation with a global make-to-order manufacturing company. This pilot company called Company A needs a generic, modular simulation game to train its whole personnel, over 1000 persons. The idea of the training game is to help the participants to better understand the causal relations between operations and money in a complex enterprise system. The game is realized using multimedia, simulation tools and social role-play. The work is accomplished as a collaborative effort of Industrial Economics, Industrial Psychology, and Telecommunication Software and Multimedia. In addition, the representatives of Company A participate in the development through actively testing the game prototypes throughout the project.

\section{DEVELOPMENT TARGETS AND METHOD}

\subsection{Targets of Enterprise Game}

According to Riis and Smeds (1998), one of the challenges for simulation games is to create an interaction of disciplines and functions, and industrialists and students in the game. Our aim is to create, with the Enterprise Game, an experimental learning environment for both practitioners and students.

By applying multimedia, we integrate into the game model the material, information and monetary flows of business processes. The game includes computer-aided visualization and simulation, and social role-play. The players represent different roles, which represent different functions of an enterprise system (Figure 1).

There is always a temptation to include too many details in one game to reflect the complex reality, whereby the game becomes confusing to the participants and its learning effects might be reduced. Additional targets and problems should rather be addressed through different games or different versions of a game (Riis et al. 1995). 


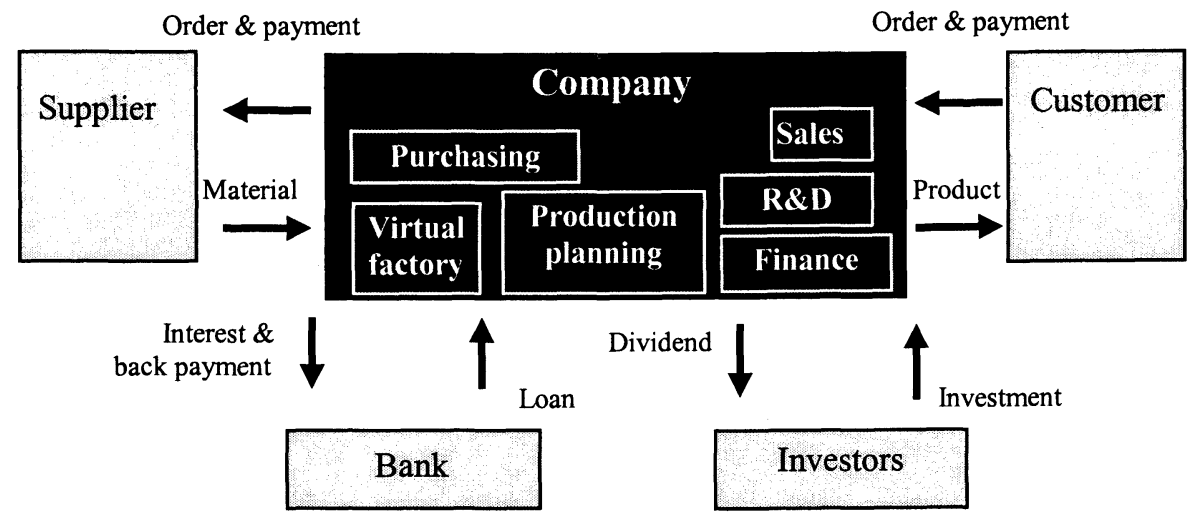

Figure 1. Model of financial and material flows in the order-to-delivery process of an enterprise.

A computerized game can solve this problem, if it is constructed in a modular way. The Enterprise Game is developed according to this principle. Three different levels of the Enterprise Game will be developed, to serve different learning targets of the participants (Table 1). Game One is a basic game where the operations of the order-to-delivery process of a generic factory are emphasized. Game Two considers project management, and Game Three strategic decisions. This paper concentrates in more detail on Game One.

Table 1. Different levels and target groups of the Enterprise Game

\begin{tabular}{|l|l|l|}
\hline LEVEL & LEARNING TARGETS & TARGET GROUP \\
\hline $\begin{array}{l}\text { Game } \\
\text { One }\end{array}$ & $\begin{array}{l}\text { Common understanding of an order-to- } \\
\text { delivery process, emphasis on } \\
\text { operational decisions }\end{array}$ & $\begin{array}{l}\text { Production workers, } \\
\text { supervisors }\end{array}$ \\
\hline $\begin{array}{l}\text { Game } \\
\text { Two }\end{array}$ & $\begin{array}{l}\text { Management of projects, emphasis on } \\
\text { operational planning and decision } \\
\text { making }\end{array}$ & $\begin{array}{l}\text { Supervisors, } \\
\text { middle managers }\end{array}$ \\
\hline $\begin{array}{l}\text { Game } \\
\text { Three }\end{array}$ & $\begin{array}{l}\text { Management of a project oriented } \\
\text { business, emphasis on strategic planning } \\
\text { and decision making }\end{array}$ & $\begin{array}{l}\text { Middle managers, } \\
\text { top managers }\end{array}$ \\
\hline
\end{tabular}

Game One focuses on the crucial interrelationships between sales, production and profitability in an order-to-delivery process. The players run the enterprise as a team, with the target to reach highest possible performance. The game contains roles that are essential for the process: 
Customer, Salesman, Designer, Production Manager, Production planner, Purchaser and Supplier.

\subsection{Prototype method}

The development of Enterprise Game One is actualized through prototypes, which are tested together with the representatives of pilot Company A. We aim to create together a training game relevant for industry and academia, generic but still realistic enough. Between the pilot tests, intermediate prototypes are tested internally by SimLab researchers only. In the test sessions, the content and the visualization of the game are addressed. The results of previous game prototypes are used to develop the game further, with sharpened objectives and structure.

In the development of Game One prototypes, we started with mock-ups', paper versions, which were like simple board games, but easier and quicker to accomplish. To design the increasingly computerized versions, we have used Visual Basic. It is a tool for rapidly creating user interfaces and assigning functionality to different widgets. In fact, it is a complete programming language of its own and allows the construction of very complex user interfaces, if necessary.

\section{THROUGH PROTOTYPES TOWARDS COMPUTERIZED MULTIMEDIA GAME}

\subsection{Manual board games as reference}

Both the SimLab researchers and the representatives of Company A had previous experiences about games as training method. The company had mainly used board games. In addition they had also participated in a traditional computerized business game. To create a joint experience and frame of reference for the development work, the company representatives and the researchers tested together two existing commercial games, both of which were board games and based on teamwork. The first game focused on production control principles, and the second one dealt with managing projects in a competitive market.

These game experiences were discussed with the company representatives to develop useful features for the new Enterprise Game. Summing up, the first manual game had illustrated the advantages of a justin-time system in a clear way. In addition it was possible to run it quickly. The second game had already before been successfully used for personnel 
training in Company A. They had found the game visual and structurally clear, it had given a general view of the dynamics of the market economy. They also appreciated the team work based design of the game. A negative feature of the second game was its long duration and the complexity of its rules.

\subsection{Increasing computerization through prototyping}

The first game prototypes were based on the features of a manual game, i.e. human communication and decision making around a joint game board, but they already utilized the calculation strength of a computer. The applied software was a discrete event simulation tool, normally utilized in the simulation of production systems, and not in games. The idea of these first prototypes was to express all the essential business functions very roughly, to test the logic of the game keeping the duration of the games in a few hours.

The first prototype was built quickly, based on the experiences of existing games. There were eight participants in different player roles, who handled an order from the order to the delivery. Order handling and production planning were realized using board game features, and the production process itself was actualized as a discrete event simulation model. The model was projected on the wall so all the participants could see it at the same time. The cash flow was illustrated manually on a wall chart.

In the joint evaluation of the first prototype, the company representatives regarded the manual production planning part as too complex and time consuming. It also took too much attention from the economic aspects of the game. In addition, the money flow should be visualized more clearly, and the costs of production should be illustrated.

The novelties in the second prototype were a new introduction to the game, and a less complex production simulation model. The game introduction, realized as a computerized slide show, acted as an orientation into the enterprise model in general, and illustrated the rules of the Enterprise Game. In the production simulation, the accumulation of production costs was now integrated and also visualized in a modest way by the computer. However, the more advanced programming of the game engine and the multimedia visualization of the material and money flow were left for next, fully computerized third prototype. 


\subsection{The computer based multimedia game prototype}

\subsubsection{The game engine and the user interfaces}

After the two first prototypes, the logic of Game One now was ready to proceed with computerization, for several reasons. Firstly, computerization increases flexibility. The modular structure of the game program will allow to adjust the game complexity to the level of knowledge of the players. Secondly, computerization saves playing time. In the previous paper based prototypes, many numbers had to be manually copied from one place to another, which forced the players to be very careful and took too much time without adding to learning. Thirdly, the computer can replace missing players. For example, the role of the Customer in the previous prototypes was mostly to accept all offers and pay money, similarly the Supplier only sent the ordered material and the bills. These roles are not very motivating, and can very well be played by a computer. If some of the players were absent, the computer could also be used to replace them.

The new game engine for the third prototype was programmed in the Java programming language. Six functions of the order-to-delivery process were played by human players: Sales, R\&D, Production Planning, Purchasing, Finance and Production. Each of these functional roles had a dedicated PC with a specific user interface, connected via a local network to the game engine. The game engine played the roles of Customer and Supplier, which are only routine roles in Game One.

Production was designed to take place in an interactive, Virtual Factory, which produced imaginary general-purpose robots called ARSCAs (Automatic Robot for Security, Cleaning \& Assembly). The Virtual Factory was programmed using Open Inventor, and the product ARSCA was modeled with 3D Studio MAX. These tools allow three-dimensional visual modeling, useful for a multimedia game. The virtual factory with its real time material flow was projected on a huge general screen, the so-called virtual wall. The second general screen showed the economic output of the order-to-delivery process like cash flow and costs, and profit and loss account.

Game One is realized as a hierarchical game model, where a server runs the game engine and the dedicated role PCs are its clients. This architecture allows the control of the game to stay in the hands of the game engine only, thus simplifying the IT solution. 


\subsubsection{Virtual reality and social interaction}

The goal of visualization in Game One was to make the Virtual Factory and its ARSCA products to look fascinating so that people would be motivated to play the game, and realistic enough that they could recognize in them some familiar features from their everyday work in the real factory. In reality, Company A produces engines, turbines and generators and it has factories familiar to the Virtual Factory.

The virtual ARSCA robots are meant to work in the nuclear power plants where also the real products of Company A are placed. The design of ARSCA is fit to its demanding tasks in surroundings that can be very risky or inconvenient for people. The power rises from the technology inside the robot - big muscles would only be unnecessary and impractical. Special legs and arms and fashionable design steel jackets in different sizes allow the flexible customization of ARSCA. (Figure 2)

A snapshot of the Salespersons screen, a picture from the virtual factory and the product, ARSCA, are shown in the Figure 2.
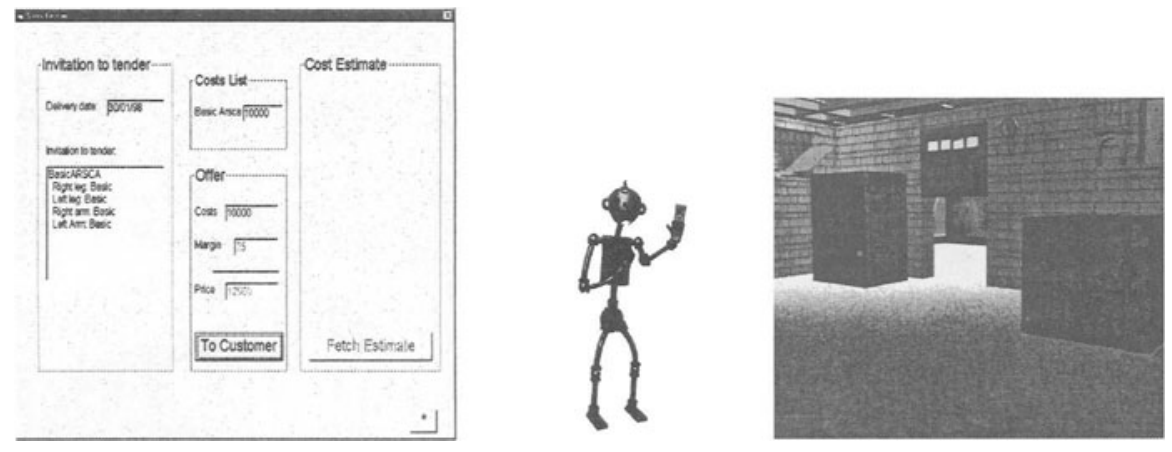

Figure 2. From left to right: A snapshot of the Salespersons screen, a view from the virtual factory, and the product ARSCA.

Each role is played by a pair of two participants, to relieve the social interaction and discussion of the participants during the game. The participants have to solve the occurring problems together before the game can continue. The game facilitator supports the experimentation and guides the discussion both during and after the game. Firstly, the facilitator has to highlight essential learning issues and secondly, to enable and ensure that everybody takes part actively. The facilitator uses the shared Visual 
enterprise model to point out the highlights, in order that the students could learn primarily by experimenting together.

In the first test game, one order was followed through the process, and the functionality of all player screens and of the general view on the wall were evaluated. At present, the prototype is developed to run in a multiple order situation and to handle disorders in the production flow.

\section{COMPARISON OF THE PROTOTYPES}

The third prototype of Game One already integrates to a large extent conceptual, computational, visual and social enterprise models into a comprehensive 'virtual enterprise', where the participants can together run the order-to-delivery process. The increasing level of computerization and visualization in the development of Game One can be seen in Table 2 (Smeds et al. 1998).

Table 2. The models of the enterprise system in the three prototype games.

\begin{tabular}{|c|c|c|c|}
\hline Model & \begin{tabular}{|l|} 
Prototype I \\
June 1998 \\
\end{tabular} & \begin{tabular}{|l} 
Prototype II \\
September 1998 \\
\end{tabular} & $\begin{array}{l}\text { Prototype III } \\
\text { May \& August } 1999\end{array}$ \\
\hline Conceptual & \begin{tabular}{|l|} 
Simple process \\
chart of the order- \\
to-delivery process
\end{tabular} & $\begin{array}{l}\text { Chart of the order-to- } \\
\text { delivery process, game } \\
\text { introduction, basic concepts }\end{array}$ & $\begin{array}{l}\text { Chart of the order-to-delivery } \\
\text { process, game introduction, } \\
\text { basic concepts }\end{array}$ \\
\hline Computational & $\begin{array}{l}\text { Production process } \\
\text { as a discrete event } \\
\text { numerical } \\
\text { simulation model } \\
\text { with modest } \\
\text { visualization } \\
\end{array}$ & $\begin{array}{l}\text { Production and production } \\
\text { costs simulated on discrete } \\
\text { event numerical simulation } \\
\text { model }\end{array}$ & $\begin{array}{l}\text { Material, information and money } \\
\text { flow modeled in the game } \\
\text { engine and in the user PC } \\
\text { interfaces, applying Java and } \\
\text { Visual Basic. }\end{array}$ \\
\hline Visual & $\begin{array}{l}\text { Process chart and } \\
\text { production model } \\
\text { projected on the } \\
\text { virtual wall. } \\
\text { Manual game } \\
\text { board for order } \\
\text { handling and } \\
\text { production } \\
\text { planning. } \\
\text { Paper money for } \\
\text { cash flow. }\end{array}$ & $\begin{array}{l}\text { Process chart, production } \\
\text { and cost flows projected on } \\
\text { the virtual wall. } \\
\text { Display of cash flow. } \\
\text { Manual game board for } \\
\text { order handling and } \\
\text { production planning. } \\
\text { Paper money for cash flow. } \\
\text { Game introduction as } \\
\text { illustrated slide show. }\end{array}$ & $\begin{array}{l}\text { Virtual reality model of the } \\
\text { factory and of the product } \\
\text { ARSCA. } \\
\text { Player tasks and information } \\
\text { flow visualized on the dedicated } \\
\text { displays. } \\
\text { Cash and cost flows projected on } \\
\text { the virtual wall. } \\
\text { Profit and loss account on the } \\
\text { virtual wall. } \\
\text { Game instruction as illustrated } \\
\text { slide show. }\end{array}$ \\
\hline Social & $\begin{array}{l}\text { A team of eight } \\
\text { players with } \\
\text { different roles runs } \\
\text { the game factory. } \\
\text { Facilitated } \\
\text { discussion during } \\
\text { the game. }\end{array}$ & $\begin{array}{l}\text { A team of eight players with } \\
\text { different roles runs the game } \\
\text { factory } \\
\text { The profit and loss account } \\
\text { and the balance sheet are } \\
\text { prepared manually by the } \\
\text { facilitator. } \\
\text { Facilitated discussion } \\
\text { throughout the game. }\end{array}$ & $\begin{array}{l}\text { A team of twelve players runs } \\
\text { the game factory playing in six } \\
\text { main roles. Two roles are played } \\
\text { by the computer. } \\
\text { Profit and loss account and } \\
\text { indicators are displayed on the } \\
\text { virtual wall to calculate results. } \\
\text { Facilitated discussion throughout } \\
\text { the game. }\end{array}$ \\
\hline
\end{tabular}


Visualization through multimedia and virtual reality in Game One aims to create a more realistic and memorable experience, to increase the learning effects. However, we also emphasize the communication between the players, the social role play. The visualized simulation models allow participants to experience as multifunctional team members the operation of a complex business process. Communication in the game roles deepens the common process understanding. The discussion during and also after the game about the actions and their effects is essential for learning. - However, on the development path so far, human communication aspects in the game prototypes have so far remained quite constant (Table 2). They will be elaborated on extensively when we proceed towards the final Game One.

In the final Game One, we aim to have a configurable game structure, where the facilitator can determine what kind of problem situations can be simulated, depending on the level of knowledge and interest of the players, and on the learning targets. The user interfaces and the virtual wall displays have high usability through increased visualization, and pay special attention to the facilitator's role and the pedagogical package surrounding the game core. Thus, the last development phase of Game One requires frequent usability tests with the real target group of learners from Company A.

\section{REFERENCES}

Riis, J.O., Johansen, J. and Mikkelsen, H. (1995) Design for simulation games. In: Riis, J.O. (Eds) Simulation Games and Learning in Production Management. Chapman \& Hall, UK, 197-211.

Riis, J., Smeds, R., Johansen, J. and Mikkelsen, H. (1998) Games for organizational learning in production management. In: N. Okino, H. Tamura and S. Fujii (Eds.) Advances in Production Management Systems. Perspectives and future challenges. Chapman \& Hall, London, 327-338.

Riis, J.O. and Smeds, R. (1998): The future of simulation games: Issues and challenges. In: Smeds, R. and Riis, J.O. (Eds) Experimental learning in Production Management. Chapman \& Hall, UK, 157-164.

Schank, R. (1997) Virtual Learning: Revolutionary Approach to Building a Highly Skilled Workforce. McGraw-Hill, New York.

Smeds, R., Gröhn, M., Haho, P., Hautala, I., Jalkanen, J. and Nieminen, M. (1998) Possibilities of Multimedia in Business Process Modeling and Simulation. Paper to be presented at the 4th International Workshop on Games in Production Management, Ghent, Belgium, November 26-29, 1998.

http://msdn.microsoft.com/vbasic/

http://www.simlab.hut.fi 


\section{ACKNOWLEDGEMENTS}

This paper has been written in the SimLab project at Helsinki University of Technology (http://www.simlab.hut.fi). In the multidisciplinary research team, Päivi Haho and Janne Ikäheimonen represent industrial management, Susanna Virtanen industrial psychology, Matti Gröhn, Janne Jalkanen, Antti Latva-Koivisto and Seppo Laukkanen computer science and multimedia, and Hanna Kervinen design and multimedia. In addition, Marko Nieminen and Ismo Hautala from the Usability Research Group at HUT have contributed importantly to the research. The research is guided by Riitta Smeds, Head of the Enterprise Simulation Laboratory, industrial management, together with Tapio Takala, professor, telecommunication software and multimedia. The joint research effort of the whole project team has made this paper possible.

The research is financially supported by the following organizations, which is gratefully acknowledged: Technology Development Centre TEKES, Academy of Finland, ABB Industry Oy, Orion Corporation Orion Pharma, Tellabs Oy, Hewlett-Packard Oy and Silicon Graphics Oy.

\section{BIOGRAPHY}

\section{Susanna Virtanen}

Susanna Virtanen, MSc (Eng), is a researcher at Helsinki University of Technology, TAI Research Centre. She has been developing a computerized game together with other researchers in the SimLab-project (http://www.simlab.hut.fi). In addition to the computerized game development she is interested in simulation game method and other participative organization development tools. 